\title{
Anaplastic large cell lymphoma: clinicopathological and immunohistochemical study of 20 cases classified according to the 2016 revision of the World Health Organization classification of lymphoid neoplasms
}

\author{
Diana Brisa Sevilla-Lizcano and Carlos Ortiz-Hidalgo*
}

Department of Cell and Tissue Biology, Universidad Panamericana, Ciudad de México, Mexico

Received on March 17, 2017; accepted on August 8, 2017

Available online: February 1, 2018

\author{
KEY WORDS \\ Anaplastic large cell \\ lymphoma; \\ Anaplastic lymphoma \\ kinase; \\ CD30; \\ Immunohistochemistry
}

\begin{abstract}
Anaplastic large cell lymphoma (ALCL) is a type of non-Hodgkin lymphoma composed of CD30-positive neoplastic cells. The 2016 revision of the WHO classification of lymphoid neeplasms includes anaplastic lymphoma kinase (ALK) positive, ALK negative and breast implant associated ALCL. ALCL have distinct clinical and prognostic features between positive and negative cases. ALK-1 positive cases mostly occur in the first three decades of life while patients with ALK-1 negative are older. ALCL exhibit a very broad range of cytology appearances that include common pattern, lymphohistiocytic pattern, small-cell pattern, Hodgkin-like pattern and composite pattern. By definition, ALCL show strong CD30 staining on the cell membrane and in the Golgi region and the majority are epithelial membrane antigen positive, express one or more T-cell or Natural Killer antigens and are constantly negative for Epstein-Barr virus. We present the clinicopathologic and immunohistochemical analysis of 20 cases of ALCL studied at a single institution, classified according to the 2016 revision of lymphoid neoplasms. Nine cases were ALK-1 positive, ten ALK-1 negative, and one case as a breast implant associated ALCL ALK-1 negative. (creativecommons.org/licenses/by-nc-nd/4.0/).
\end{abstract}

${ }^{*} E$-mail for correspondence: ortizhidalgocarlos@gmail.com (C. Ortiz-Hidalgo) 


\section{INTRODUCTION}

Originally described by Stein et al. in 1985, anaplastic large cell lymphoma $(A L C L)$, is an aggressive lymphoma with $\mathrm{T}$ or null immunophenotype that characteristically expresses CD30 (TNF receptor-associated factor/Ki-1-BerH2) on the membrane and paranuclear zone of neoplastic cells. It accounts for $1-2 \%$ of adult non-Hodgkin lymphomas (NHL) and up to $15 \%$ of lymphomas in children ${ }^{1,2}$. Some ALCLs have the $\mathrm{t}(2 ; 5)(\mathrm{p} 23 ; \mathrm{q} 35)$ translocation, which was cloned in 1994 by Morris; subsequently, in 1997, the antibody that detects its gene, anaplastic lymphoma kinase (ALK), was produced, which then enabled the division of this lymphoma in two entities: those that express ALK and those that don't $\mathrm{t}^{3-6}$.

ALCL has two clinical presentations: cutaneous and systemic. The cutaneous form corresponds to the category known as "CD30+ lymphoproliferative cutaneous disorder", which includes, on one side of the spectrum, lymphomatoid papulosis, and, on the other, primary cutaneous $\mathrm{ALCL}^{12}$. The systemic form is an aggressive lymphoma where, clinically, patients are present with advanced stages of the disease (stages III or IV), and it involves mainly the lymph nodes, but it can compromise the bone, the skin, soft tissues and lungs as well ${ }^{7}$. The last revision in 2016 of the World Health Organization (WHO) classification of lymphoid neoplasms includes three variants in systemic ALCL: ALK-1+ ALCL, ALK1- ALCL and breast implant-associated ALK-1- ALCL ${ }^{6}$.

The purpose of this work is to present the clinicopathological and immunohistochemical study of 20 cases analyzed in a single institution, with an emphasis on the new division proposed by WHO for this type of lymphomas.

\section{MATERIAL AND METHODS}

The files of Centro Médico ABC (CMABC) Department of Surgical and Molecular Pathology were searched for cases coded with the ALCL diagnosis within a 16-year period (from 2000 to 2016), with those localized on the skin being excluded. Twenty cases were found, and clinical data such as gender, age and location were obtained, as well as the histological diagnostic report. Out of these 20 cases, 16 (16/20 [80\%]) corresponded to external materials received for consultation, and 4, to patients admitted to the CMABC.

For the diagnosis of $\mathrm{ALCL}$, the criteria used (according to $\mathrm{WHO}$ ) were the following: by hematoxylin-eosin, presence of cohesive groupings of large, pleomorphic cells with abundant cytoplasm and irregular kidney- or horseshoe-shaped nuclei, which have been referred to as hallmark cells, and that display disperse, vesicular chromatin and a single nucleolus or two or more small nucleoli, accompanied by abundant mitoses in an inflammatory or fibrotic background. These cells had to be present at least at a minimal proportion in any ALCL variant. In addition, the neoplastic cells had to diffusely and intensely express CD30 on the cell membrane and the Golgi zone ${ }^{3}$. The expression of T-cell markers was variable, as well as that of EMA and ALK. The WHO indicates that ALCL may have several histological patterns: classic or common $(60 \%)$, lymphohistiocytic $(10 \%)$, small cells $(5-10 \%)$ and Hodgkin-type (3\%) (see below) ${ }^{6}$.

$3-\mu \mathrm{m}$ sections were obtained from the 20 paraffin blocks and stained with hematoxylin and eosin. For diagnosis, immunohistochemistry analysis was performed with CD20 (BioSB/L26/1:500), CD30 (BioSB/BerhH2/1:100), EMA (Dako/Ep5/1:200), Ki67 (BioSB/EP5/1:50), ALK-1 (Dako/ ALK-1/1:30) and CD3 (BIOCARE/M/1:50), and in some assays, CD45R0 (BioSB/UCHL-1/1:50), CD4 (BioSB/RBT-CD4/1:50), CD8 (BioSB/144B/1:200), CD5 (BioSB/RBT-CD5/1:100) and CD43 (BioSB/MT1/1:30) were used.

\section{RESULTS}

Of the $20 \mathrm{ALCL}$ cases, $9(9 / 20$ [45\%]) were ALK+ and $11(11 / 20[55 \%])$ were ALK-. Of the ALK+ALCL cases, 6 (6/9 [66\%]) were females and $3(3 / 9$ [33\%]) were males, with ages ranging from 9 to 68 years (average: 26 years). Of the ALK- ALCL cases, 4 (4/11 [37\%]) were females and 7 (7/101 [63\%]) were males, with ages ranging from 17 to 79 years (average: 46 years) (Table 1).

With regard to the location of the 9 cases of ALK+ lymphomas, the most common was the lymph nodes (7 [78\%]; there were four cases in the cervical lymph nodes, one in retroperitoneal lymph node, two in lymph nodes (localization was not specified in the referral report), one at chest wall region soft tissue lymph nodes and one in the lung.

With regard to the 11 ALK- cases, the localization was the lymph nodes in seven cases (two in cervical, two in supraclavicular, two in inguinal lymph nodes and one with no specified localization), and there were four cases of extranodal localization (one in the maxillary sinus, one in the lung, one in the intestine and one was related to a breast implant); the latter case corresponded to a 52-year old woman (see below).

\section{Morphological features}

All ALK+ ALCL cases had the common or classic-type morph 8 logical characteristics (7/9), except for two cases that had the lymphohistiocytic variant. In all cases was there geogra phic necrosis and focal sclerosis with multinodular appearance (Fig. 1A). Neoplastic cells were large, oval-shaped or pleomorphic, and had abundant pale-to-eosinophilic cytoplasm and eccentric, irregular nuclei, with disperse chromatin and occasional prominent nucleoli (Fig. 1 B). In some areas, neoplastic cells were epithelioid with horseshoe-shaped nuclei and a paranuclear eosinophilic region, which was consistent with the so-called hallmark cells (Fig. 1 B, arrowf. In some cases, malignant cells were grouped around blood vessels (Fig. $1 \mathrm{C}$ ), mitoses were common and there was variable degree of mixed inflammatory infiltrate composed of small lymphocytes, histiocytes and eosinophils in the cetl environment (Fig. 2). In the cases with lymph node involvement, there were scarce residual germinal centers disperse among neoplastic cells predominating in the paracortex and extending up to the subcapsular space, mimicking a metastatic carcinoma. Other cases showed nodal architecture total loss with diffuse infiltration by cohesive groups of neoplastic cells. The lymphohistiocytic variant was present in two cases, one of them in a lymph node and the other in the rib cage soft tissues, which were characterized for having larger numbers of histiocytes and inflammatory cells that were predominant and obscured malignant lymphoid cells, mimicking reactive inflammatory histiocytic processes or hemophagocytic syndrome (Fig. 3 A). 
Table 1. ALCL cases

\begin{tabular}{|c|c|c|c|c|}
\hline Gender & Age & Localization & Histological variant & ALK expression \\
\hline Female & 19 & Cervical lymph node & Lymphohistiocytic & Positive \\
\hline Female & 13 & Cervical lymph node & Classic & Positive \\
\hline Female & 26 & Cervical lymph node & Classic & Positive \\
\hline Female & 68 & Lymph node, not specified & Classic & Positive \\
\hline Female & 35 & Rib cage (soft tissue) & Lymphohstiocytic & Positive \\
\hline Male & 37 & Lung & Classic & Positive \\
\hline Male & 12 & Lymph node, not specified & Classic & Positive \\
\hline Female & 9 & Cervical lymph node & Classic & Positive \\
\hline Male & 21 & Retroperitoneal lymph node & Classic & Positive \\
\hline Male & 36 & Supraclavicular lymph node & Sarcomatoid & Negative \\
\hline Male & 79 & Maxillary sinus & Classic & Negative \\
\hline Male & 32 & Supraclavicular lymph node & Lymphohistiocytic & Negative \\
\hline Female & 64 & Inguinal lymph node & Classic & Negative \\
\hline Male & 70 & Cervical lymph node & Classic & Negative \\
\hline Female & 38 & Inguinal lymph node & Classic & Negative \\
\hline Male & 51 & Cervical lymph node & Classic & Negative \\
\hline Male & 17 & Lung & Classic & Negative \\
\hline Male & 21 & Intestine & Classic & Negative \\
\hline Female & 49 & Lymph node, not specified & Classic & Negative \\
\hline Female & 52 & Breast (implant) & Classic & Negative \\
\hline
\end{tabular}

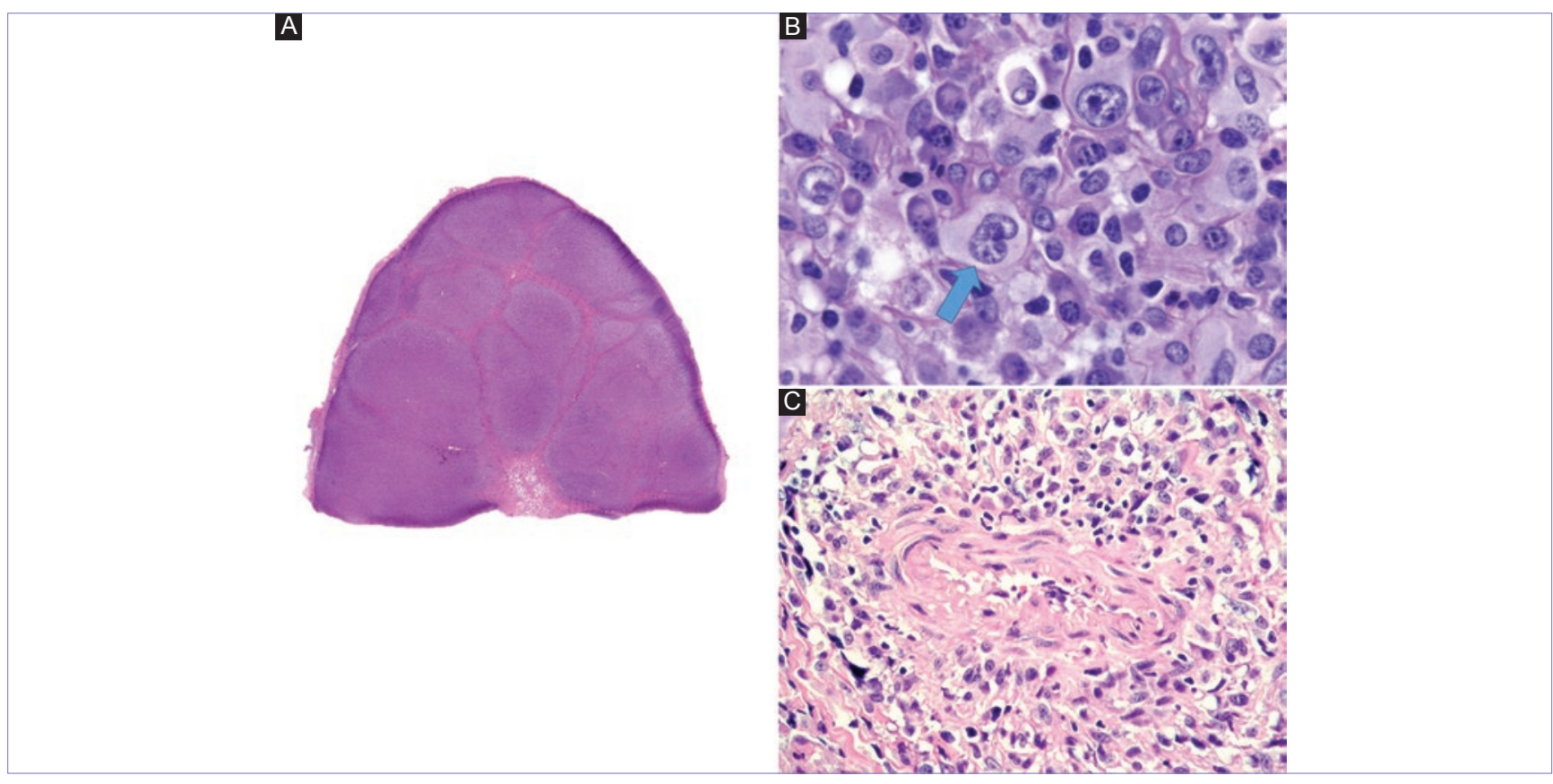

Figure 1. Common-type ALCL. A: multinodular architecture. B: neoplastic cells are large, oval-shaped or pleomorphic, and show abundant pale to eosinophilic cytoplasm, some with eccentric, irregular nuclei, with disperse chromatin and occasional prominent nucleoli and cells with horseshoe-shaped nuclei and a paranuclear eosinophilic region, which are the so-called hallmark cells (arrow). C: neoplastic cells can be distributed around blood vessels.

ALK- ALCL cases shared morphological features with ALK+ cases, and the common or classic variant was predominant $(9 / 11)$, with only one case of the lymphohistiocytic type. Unlike ALK+ lymphomas, in our case series there was one case of the sarcomatoid type with lymph node partial substitution by intertwined fascicles of fusiform pleomorphic neoplastic cells and pleomorphic epithelioid cells with horseshoe-shaped nuclei and frequent mitosis. Both these types of cell were predominant at the sinusoids and the subcapsular region in an inflammatory background mimicking a metastatic soft tissue sarcoma (Fig. 3 B). 


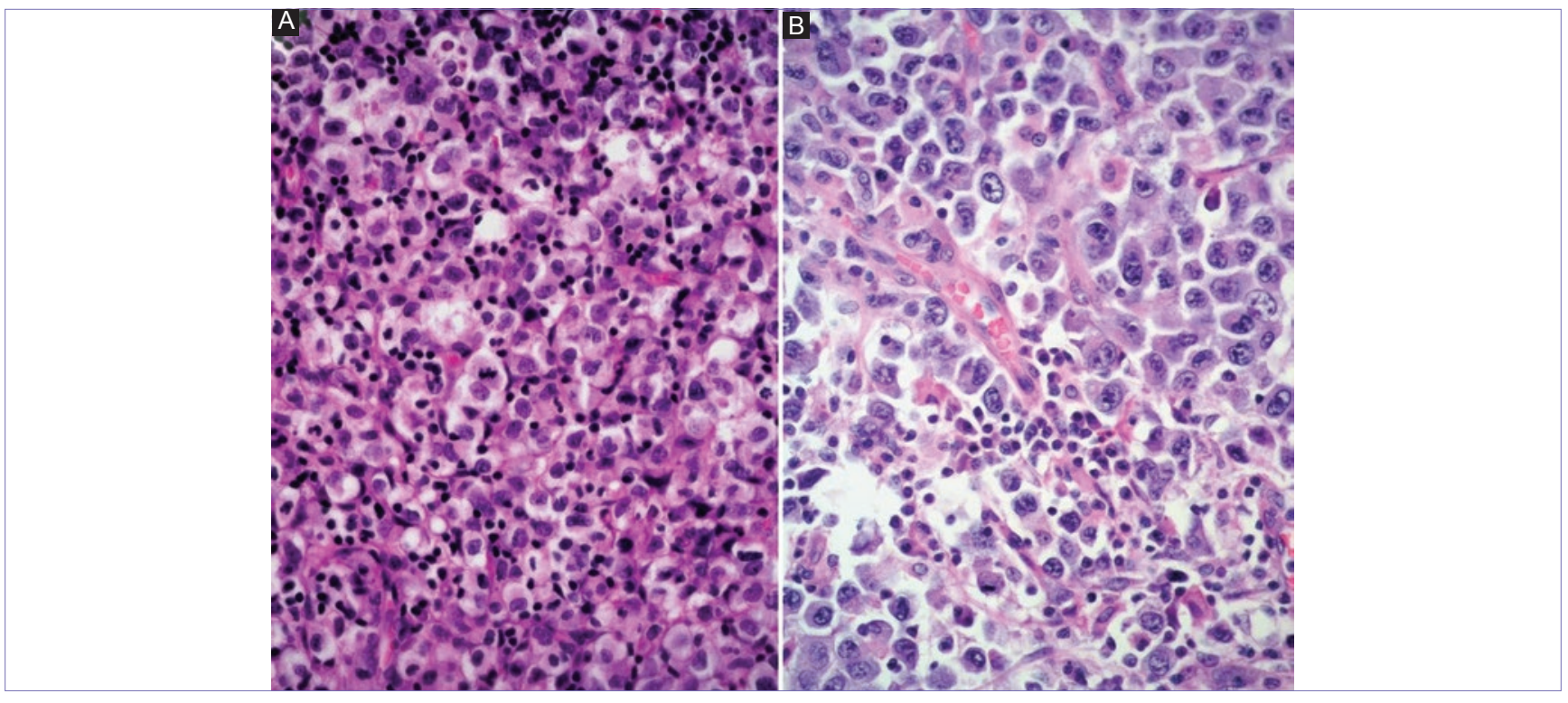

Figure 2. Classic-type ALCL, where there are frequent mitoses and variable degree of mixed inflammatory infiltrate composed of small lymphocytes, histiocytes and eosinophils in the cell environment.

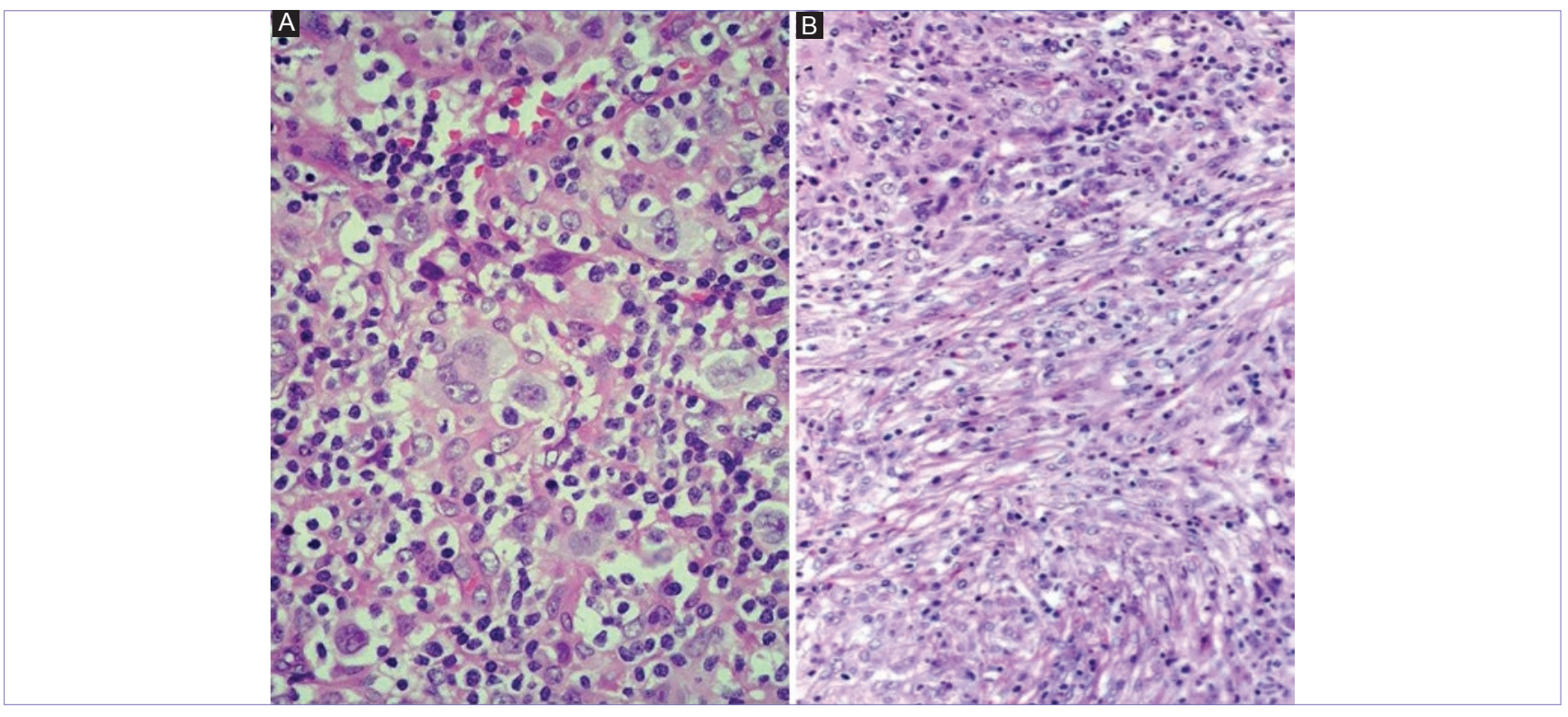

Figure 3. A: lymphohistiocytic histological variant, where histiocytes and inflammatory cells that can overshadow malignant lymphoid cells are predominant. They can mimic reactive histiocytic inflammatory processes or hemophagocytic syndrome. B: sarcomatoid variant. There are intertwined fascicles of fusiform pleomorphic neoplastic cells and pleomorphic epithelioid cells with horseshoe-shaped nuclei and frequent mitoses. This variant can mimic metastatic soft tissue sarcoma.

By immunohistochemistry, all cases were diffusely and intensely CD30-positive in the neoplastic cells membrane and with punctate accentuation in the Golgi area. EMA expression was positive in the cytoplasm and membrane of neoplastic cells, with variable expression (one case was not tested) (Fig. 4 A and B). All cases were CD20-negative.

Of the 20 cases, 4 were CD3+ (all ALK-) and 16 were CD3- (9 ALK+ and 7 ALK-). These 16 cases were variably positive for other T-cell markers such as CD45RO (8 cases), CD4 (5 cases) and CD5 (3 cases) (Fig. 4 C and D).

Cell proliferation index expression, as measured with Ki67 in ALK + ALCLs ranged from $30 \%$ to $90 \%$, with an average of $70 \%$ (Ki67 was not quantified in four cases). In ALK- ALCLs,
Ki67 was $20-80 \%$, with an average of $47.5 \%$ (Ki67 was not quantified in three cases).

Of the 9 ALK-1-positive cases, 7 (77\%) were positive in the cytoplasm and nucleus, and $2(23 \%)$ only in the cytoplasm (one of them was granular) (Fig. $5 \mathrm{~A}, \mathrm{~B}$ and C).

\section{DISCUSSION}

ALCL is a high grade lymphoma that was described by Karl Lennert's group in 1985', who reported 45 cases of a lymphoid neoplasm with pleomorphic morphology and that expressed $\mathrm{Ki}-1$ (BerH2/CD30), ${ }^{1,7}$. Ki-1, which was previously described as being selective for Reed-Sternberg (R-S) cells, 


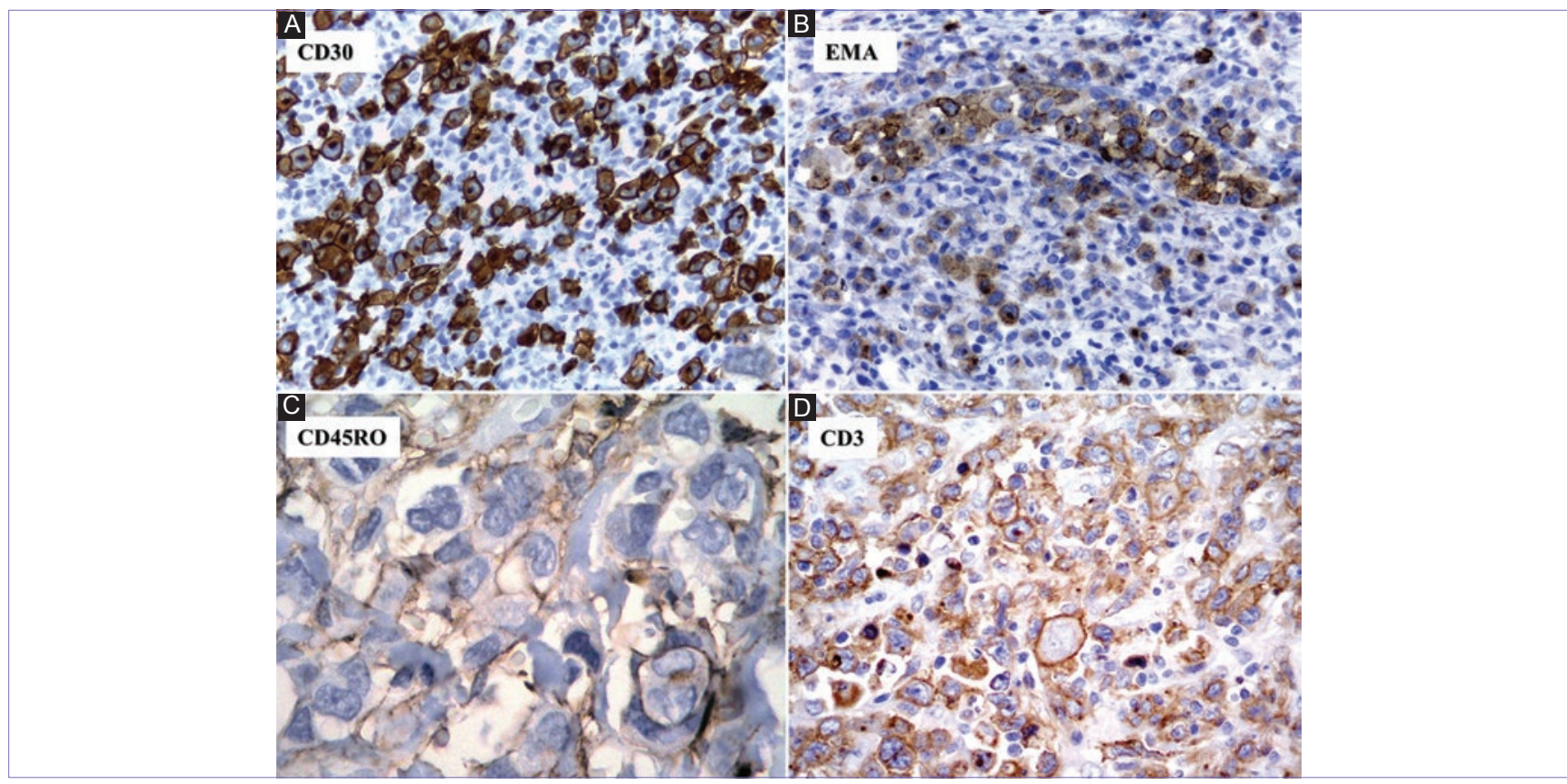

Figure 4. By immunochemistry, ALCLs are positive for CD30 (A) and EMA (B), and for T-cell markers such as CD45RO (C) and CD3 (D).

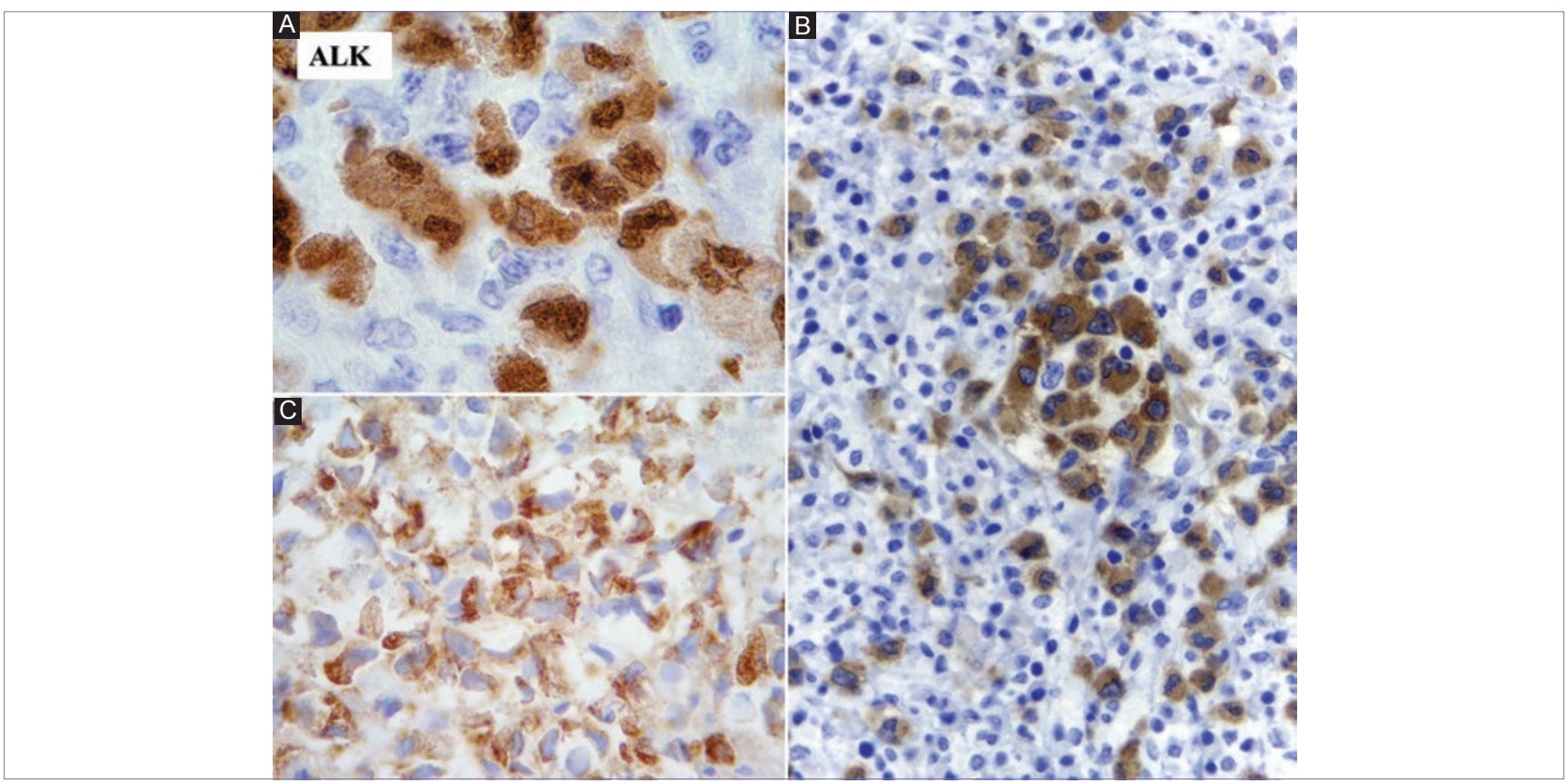

Figure 5. ALK+ ALCLs are associated with the $\mathrm{t}(2 ; 5)(\mathrm{p} 23 ; \mathrm{q} 35)$ chromosomal translocation $(A L K / N P M)$. In the classic translocation, ALK immunohistochemicâl expression characteristically occurs in the nucleus and cytoplasm (A); however, in translocation variants where other chromosomes are involved, the staining patterns can be cytoplasmic (B) or fine granular cytoplasmic (C).

was also expressed in this type of lymphoma, which had morphological features that were similar to those of histiocytes or epithelial cells, with accentuated nuclear pleomorphism, lymph node involvement predominantly at the paracortical zone, with necrosis foci and sinusoidal dissemination ${ }^{1,8}$. This lymphoma was originally named "Ki-1 lymphoma" ${ }^{4}$ and was later reclassified as lymphoid-origin activated neoplasm, and not histiocytic-origin, as previously described ${ }^{1,9,10}$. In 1988, in the Kiel classification, it was named ALCL. Subsequently, in 1994, Morris et al. discovered that the $\mathrm{t}(2: 5)(\mathrm{p} 23 ; \mathrm{q} 35)$ translocation, resulting from nucleophosmin (NPM) and ALK fusion, was associated in up to $80 \%$ of this type of lymphomas $^{3,4}$. Some years later, Pulford et al. produced the antibody that detects the ALK gene protein, which was highly useful for diagnosis ${ }^{2,5}$.

In the 2016 revision of the WHO classification of lymphoid neoplasms, ALCL is sub-classified in ALK+ ALCL, ALK- ALCL and breast implant-associated ALK- ALCL ${ }^{6}$. Primary cutaneous anaplastic lymphoma is a different disease, closely related to lymphomatoid papulosis, and it is classified within the so-called "CD30+ lymphoproliferative disorder", which has no abnormalities in the ALK gene $e^{9,11,12}$. 
Currently, ALK + anaplastic lymphoma of B-cell immunophenotype does not belong in this category and it is classified within the diffuse large B-cell lymphomas (B-DLCL) ${ }^{9,12}$.

\section{ALK+ anaplastic large cell lymphoma}

ALK+ ALCL accounts for approximately $1-2 \%$ of NHLs in adults $^{2}$ and $10-15 \%$ of lymphomas in children ${ }^{2}$. It occurs more commonly within the first three decades of life and shows a slight predominance in males ${ }^{13}$. In our series, ALK+ ALCL was more common in females, with a 2:1 ratio, an average age of 28 years (range: $9-68$ years); in males, average age was 23 years (range: $12-37$ years). In up to $70 \%$ of patients it is at advanced stages (III-IV) at diagnosis, with involvement mainly of intra-abdominal and mediastinal lymph nodes, associated with B symptoms. There is common extranodal dissemination to the skin (30\%), followed by the liver, lung, soft tissues and bone ${ }^{2,9,12}$. In our cases, predominant involvement was in the cervical lymph nodes, and one occurred as a primary lesion in the lung and another primary in the rib cage soft tissues. Central nervous system and gastrointestinal system involvement is rather infrequent ${ }^{2,9,14,15}$.

The WHO recognizes five ALK+ ALCL morphological variants: classic or common (70-78\%), small-cell (10\%) (Fig. 6A), lymphohistiocytic (10\%), Hodgkin-like (1-3\%) (Fig. 6 B) and with composite pattern ${ }^{2}$. The most common variant in our work was the classic one (77\%), followed by the lymphohistiocytic pattern $(23 \%)$. There was no other variant.

Other, less common histological patterns have also been described, including the giant cell-rich ALCL pattern (abundant multinucleated giant cells, some of the R-S-type $)^{4}$, the sarcomatoid pattern (which can mimic a lymph-node metastatic Kaposi's sarcoma), with myxoid stroma (fasciitis-type), with signet ring cells (Fig. 6 C) and with cytoplasmic vacuolizations (Fig. 6 D). The importance of recognizing these unusual variants lies in avoiding misdiagnosis with serious clinical consequences.

One of classic or common ALCL main morphological features is that it shows sinusoidal growth with common necrosis, which can resemble a metastatic carcinoma. Hallmark cells are common, and are immerse in an inflammatory background, and there can be cells resembling R-S cells, as well as abundant mitoses ${ }^{4}$. When neoplastic cells spread to the paracortex, they distribute cohesively forming cell sheets ${ }^{16}$. Differential diagnosis of this pattern in adult patients includes metastatic carcinoma (it is positive for several cytokeratines and EMA), metastatic melanoma (it is positive for S100 protein, HMB45, Melan A and MITF1), embryonic caicinoma (it is also positive for CD30, but, morphologically, it has higher degree of pleomorphism than ALCL and expresses several keratins, OCT3/4 and SALL4) and peripheral T-cell lymphoma, not otherwise specified (PTCL-NOS) (it is positive for CD3 and BCL2 and weak or negative for CD30) (Fig. 7).

Lymphohistiocytic-pattern ALCL is characterized for having neoplastic cells often grouped around blood vessels and for the presence of large numbers of histiocytes (macrophages). Typically, histiocytes have finely granular eosinophilic cytoplasm and uniform, round and small nuclei, and are sư rrounded by numerous inflammatory cells, including neutrophils, eosinophils and plasma cells. Occasionally, histiocytes exhibit erythrophagocytosis. Caution should be exercised with this variety, since such an intense inflammation can mask malignant cells, which are often smaller than in the common pattern, which may lead to misdiagnosis of a reactive/inflammatory lesion. The key for diagnosis is suspecting this neoplasm and using immunohistochemistry with antibodies against CD30 and ALK. Generally, there are no well-formed granulomas or epithelioid cell large groups ${ }^{17}$.

Small-cell ALCL has a predominant population of small/medium-size cells with irregular nuclei and abundant, clear cytoplasm resembling "fried egg" cells; hallmark cells

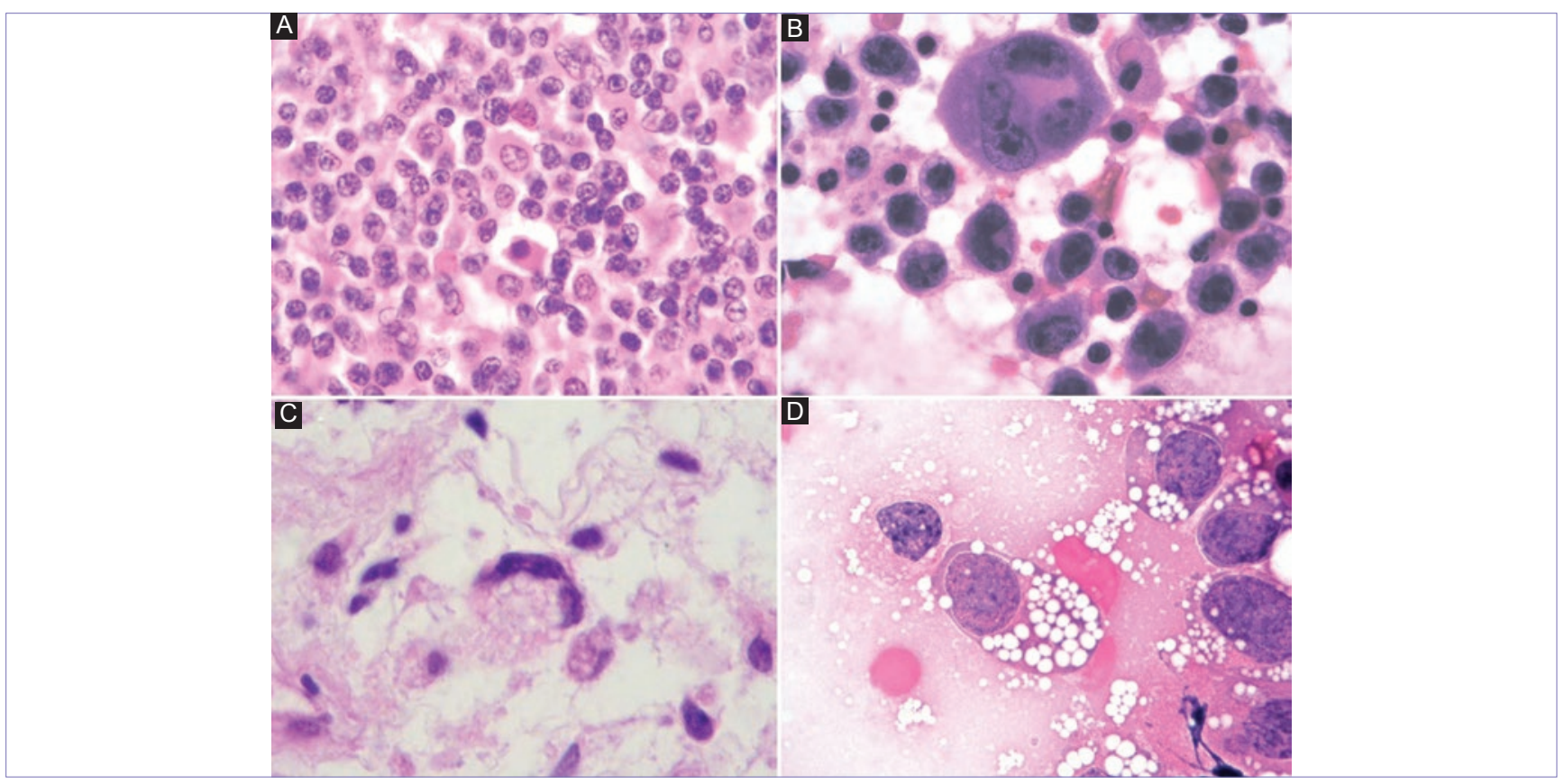

Figure 6. Among the variants ALCL can have, the following are included: small cell (A), Hodgkin-type (B), with signet ring cells (C) and with cytoplasmic vacuolizations (D). It's important to recognize these unusual variants in order to avoid misdiagnosis with serious consequences. 


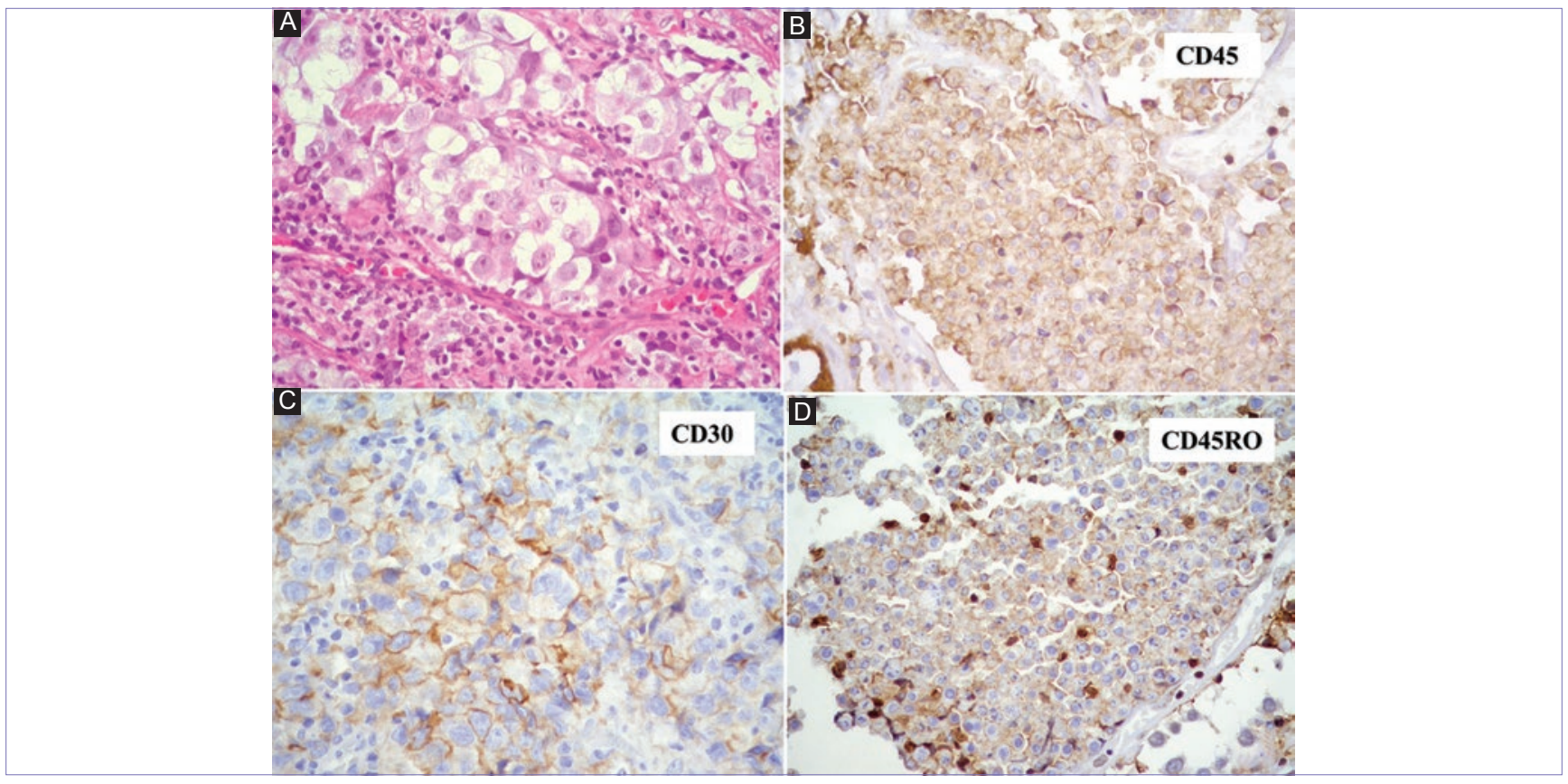

Figure 7. ALCL with germ-cell tumor histological pattern. A: hematoxylin and eosin showing groups of neoplastic cells surrounded by thin fibrous septa and chronic inflammation mimicking a seminoma. However, by immunostaining, neoplastic cells are positive for CD45 (B), CD30 (C) and CD45RO (D).

are present, but they are not that numerous and are usually found around blood vessels. This variant is often diagnosed as PTCL-NOS, but hallmark cells perivascular distribution may be useful to establish the diagnosis. In this variant, tumor cells can be only weakly positive or even negative for CD30 and positivity for ALK is often restricted to the nucleus of neoplastic cells. In this situation, positivity for CD4, CD43 and EMA can aid diagnosis (Table 2).

Hodgkin-type ALCL is characterized for having similar morphologic traits to classic Hodgkin's lymphoma nodular sclerosis variant. These cases display nodular fibrosis with capsular thickening and cells resembling R-S cells intertwined with hallmark cells. The expression of CD30 and ALK, as well as of some T-cell markers, such as CD4, CD43 and EMA, corroborate the Hodgkin-type ALCL diagnosis ${ }^{18}$ (Table 2).

By definition, ALCL is positive for CD30 $(100 \%$ at the membrane and the Golgi zone), although in the small cell variant some neoplastic cells can be negative, with focal EMA expression in most cases ${ }^{2,9}$. The ALK protein is usually positive at the nucleus and cytoplasm of malignant cells, as it occurred in most our cases, but this expression is variable and can only occur at the cytoplasm or the cell membrane, since it depends on the type of translocation that is present (Table 3).

$\mathrm{ALK}+\mathrm{ALCL}$ is regarded as a T-cell lymphoma; however, more than $75 \%$ of cases are CD30-, which is consistent with all our nine ALK+ cases, all of them CD30-2,10. Of these CD30- cases, more than $90 \%$ had a T-cell receptor (TCR) clonal rearrangement ${ }^{16}$. CD4 is the T-cell marker that is preserved in most ALK+ ALCL cases when compared with other T-cell markers such as CD2, CD3, CD5 and CD7, and also neoplastic cells are positive for CD45, CD45RO and CD25 $5^{19}$. In our cases, we used CD4, CD45RO and CD5 to corroborate the lesions' T-cell lineage. When there is no expression for any T-cell marker in ALCL cases (corroborated by positivity for CD30, EMA and ALK), these are classified as null-cell phenotypes, and are regarded as the same disease than $\mathrm{T}$-cell $\mathrm{ALCL}^{10}$. Most ALK+ ALCLs express one or more markers for NK cells, such as CD56, the expression of which, as previously demonstrated, entails a worse prognosis ${ }^{14,16}$. There is also expression of cytotoxic proteins such as perforin, TIA-1 and granzyme B, and CD43 is positive in more than $75 \%$ of cases but, although its expression can favor the T-cell immunophenotype, it is unspecific, since it is also expressed $\min$ some B-cell lymphomas ${ }^{10}$. In our cases, we used CD43 in five cases, and it tested positive in four of them. CD8 is usually negative, but there are reports of positive cases. Some cases are positive for CD68/KP1, but not for CD68/PGM1, and most ALK+ ALCLs are negative for $B C L 2^{2,19}$. In addition, these lymphomas have been reported to be able to show immunereactions to myeloid markers such as CD33 and CD13, as wefl as $p 63^{2}$. There is positivity for clusterin in $80-100 \%$ of ALCLs, but not in primary skin $\mathrm{ALCLs}^{11}$.

Neither ALK+ nor ALK- ALCLs have immunoreaction for VEB both by immunochemistry (latent membrane protein-d [LMP-1]) and by in situ hybridization and EBV-encoded smati RNA (EBER) 19 .

ALK+ ALCLs are associated with a specific chromosomat translocation, $\mathrm{t}(2 ; 5)(\mathrm{p} 23 ; \mathrm{q} 35)$, with fusion of the kinase gene $A L K$ to the nucleolar protein gene NPM 1. The translocation breakpoint gene product is the fusion gene NPM-ALK, which is oncogenic owing to its structural functions ${ }^{10}$. In this $\mathrm{t}(2 ; 5)(\mathrm{p} 23 ; \mathrm{q} 35)$ classic translocation, ALK immunohistochemical expression is characteristically in the nucleus and the cytoplasm; however, in translocation variants where other chromosomes are involved, staining patterns are different (Fig. 5 and Table 2) ) $^{19,20 .}$

The importance of $A L K+A L C L$ lies in that it has better prognosis than ALK-negative cases, with no significant prognostic differences between each variant of the translocations that affect the ALK gene. ALK+ ALCLs are sensitive to chemotherapy and to therapy with anti-ALK 
Table 2. Differential diagnosis table

\begin{tabular}{|c|c|c|}
\hline Entity & Immunohistochemistry & Comments \\
\hline Common type ALCL & $\begin{array}{l}\text { CD30+, EMA+, ALK+ (85\%), CD45-/+, } \\
\text { CD3-/+, CD43+, CD2-/+, CD4-/+, CD5-/+, } \\
\text { CD7-/+, CD8-/+, cytotoxic proteins }+/-, \\
\text { BCL2- (most cases) }\end{array}$ & Sinusoidal growth pattern, hallmark cells \\
\hline \multicolumn{3}{|l|}{ Metastasis } \\
\hline Carcinoma & Cytokeratin +, EMA+, CD30-, CD45- & Rare $\mathrm{CD} 30+$ cases \\
\hline Melanoma & S-100+, EMA-/+, HMB45+, PNL2+, CD45- & Weak CD30 has been reported \\
\hline $\begin{array}{l}\text { PTCL-NOS with } \\
\text { predominant large cells }\end{array}$ & $\begin{array}{l}\mathrm{CD} 30-/+, \mathrm{EMA}-/+, \mathrm{ALK}-, \mathrm{CD} 3+, \mathrm{CD} 2-/+ \text {, } \\
\mathrm{CD} 4-/+, \mathrm{CD} 5-/+, \mathrm{CD} 7-/+, \mathrm{CD} 8-/+ \text {, cytotoxic } \\
\text { proteins * } \\
+/-, \mathrm{BCL} 2\end{array}$ & $\begin{array}{l}\text { Rare cases with growth and pleomorphic } \\
\text { cell patterns }\end{array}$ \\
\hline$A L K+D L C L$ & $\begin{array}{l}\text { CD30-, EMA+, ALK+, CD20/CD79a-, } \\
\text { cytoplasmiclgA }\end{array}$ & $\begin{array}{l}\text { Sinusoidal growth pattern } \\
\text { Immunoblasts or plasmablastic cells }\end{array}$ \\
\hline $\begin{array}{l}\text { B-DLCL, anaplastic } \\
\text { variant }\end{array}$ & CD30-/+, EMA-/+, ALK-, CD20/CD79a+ & Some with sinusoidal pattern, but ALK- \\
\hline Histiocytic sarcoma & $\begin{array}{l}\text { CD30-, EMA-, ALK-, CD68+, CD163+, } \\
\text { lysozyme + }\end{array}$ & \\
\hline Lymphohistiocytic ALCL & $\begin{array}{l}\mathrm{CD} 30+, \mathrm{EMA}+, \mathrm{ALK}+, \mathrm{CD} 68-, \mathrm{CD} 45-/+ \\
\mathrm{CD} 3-/+, \mathrm{CD} 43+, \mathrm{CD} 2-/+, \mathrm{CD} 4-/+, \mathrm{CD} 5-/+ \\
\mathrm{CD} 7-/+, \mathrm{CD} 8-/+, \text { cytotoxic proteins }+/-\end{array}$ & $\begin{array}{l}\text { Sinusoidal growth pattern can be absent, } \\
\text { but perivascular pattern is present in all } \\
\text { cases } \\
\text { Only reactive histiocytes are CD68+ }\end{array}$ \\
\hline $\begin{array}{l}\text { Histiocyte-rich } \\
\text { lymphadenitis }\end{array}$ & CD30-, EMA-, ALK- & $\begin{array}{l}\text { Rare } C D 30+\text { immunoblasts } \\
\text { No perivascular pattern }\end{array}$ \\
\hline $\mathrm{ALCL}$, small cell variant & $\begin{array}{l}\mathrm{CD} 30+, \mathrm{EMA}+, \mathrm{ALK}+, \mathrm{CD} 45-/+, \mathrm{CD} 3+\text { (most } \\
\text { cases), CD43+, CD2+/-, CD4+/-, CD5+/-, } \\
\mathrm{CD} 7+/-, \mathrm{CD} 8+/-, \text { cytotoxic proteins }+\end{array}$ & $\begin{array}{l}\text { Sinusoidal growth pattern can be absent, } \\
\text { but perivascular pattern is observed in al } \\
\text { cases. ALK is nuclear }\end{array}$ \\
\hline $\begin{array}{l}\text { PTCL-NOS with } \\
\text { intermediate to } \\
\text { small-size cells }\end{array}$ & $\begin{array}{l}\text { CD30-/+, EMA-/+, ALK-, CD45+/-, } \\
\text { CD3+ (most cases), CD43+, CD2-/+, CD4-/+, } \\
\text { CD5-/+, CD7-/+, CD8-/+, cytotoxic proteins } \\
+/-\end{array}$ & $\begin{array}{l}\text { CD30+ cells can be observed, but without } \\
\text { perivascular pattern }\end{array}$ \\
\hline Other ALCLs & $\begin{array}{l}\text { D30+, EMA+, ALK+, CD45-/+, CD3-/+, } \\
\text { CD43+, CD2-/+, CD4-/+, CD5-/+, CD7-/+, } \\
\text { CD8-/+, cytotoxic proteins }+/-, \\
\text { BCL2- (most cases) }\end{array}$ & $\begin{array}{l}\text { Sinusoidal pattern. Hallmark cells } \\
\text { Rare cases of ALK+ ALCL can express } \\
\text { paranuclear CD15+ }\end{array}$ \\
\hline Hodgkin's lymphoma & $\begin{array}{l}\text { CD30+, EMA-, CD15+/-, ALK-, CD45-, CD3-, } \\
\text { PAX5-, CD43-, CD20-/+ (heterogeneous), } \\
\text { EBV/ LMP-1+/- (60\%), variable BCL2 }\end{array}$ & $\begin{array}{l}\text { Sinusoidal growth pattern is rare. No } \\
\text { perivascular pattern }\end{array}$ \\
\hline $\begin{array}{l}\text { Inflammatory } \\
\text { myofibroblastic tumor }\end{array}$ & CD30-, EMA-, ALK+ (cytoplasm) & $\begin{array}{l}\text { ALCL with sarcomatous morphology is } \\
\text { always CD } 30+, \text { EMA+ and ALK+ }\end{array}$ \\
\hline Rhabdomyosarcoma & CD30-, EMA-, ALK-/+ (cytoplasm), desmin + & $\begin{array}{l}\text { Rare cases of rhabdomyosarcoma can } \\
\text { show positive cells for CD30 and EMA }\end{array}$ \\
\hline
\end{tabular}

monoclonal antibodies such as crizotinib, but, notwithstanding, relapses occur in up to $30 \%$ of cases $^{2}$. Five-year survival ranges from 70 to $80 \%$, unlike ALK- cases, where it is lower than $50 \%{ }^{17}$.

The $\mathrm{t}(2 ; 5)(\mathrm{p} 23 ; \mathrm{q} 35)$ translocation and/or positivity to ALK are not specific to ALK+ anaplastic lymphoma. Rarely, some B-DLCLs may have the $\mathrm{t}(2 ; 5)(\mathrm{p} 23 ; \mathrm{q} 35)$ translocation, and these neoplasms have plasmablastic morphology, are ALK-positive at the nucleus and cytoplasm, and express immunoglobulin A (IgA), but can be CD30-negative (or express it weakly ${ }^{21}$. ALK can also be expressed in some cases of neuroblastoma, inflammatory myofibroblastic tumor and rhabdomyosarcoma (alveolar) ${ }^{22}$. Interestingly, the $\mathrm{t}(2 ; 5)(\mathrm{p} 23 ; \mathrm{q} 35)$ translocation has been detected in the lymph nodes and peripheral blood of individuals with no evidence of lymphoma (few NPM-ALK cDNA copies and negativity for the ALK protein), but the meaning of this has not been clarified ${ }^{22}$.

\section{ALK- anaplastic large cell lymphoma}

In the fourth edition of the WHO classification of lymphoid neoplasms, ALK- ALCL is a provisional entity defined as "a neoplasm that is indistinguishable from its ALK+ counterpart" "18. As in ALK+ ALCL, the characteristic neoplastic cells of this ALK- lymphoma are hallmark cells, which are also CD30-positive with a phenotype that can be T-cell or null and, in addition, they express cytotoxic granules. ALK- ALCL corresponds to $15-50 \%$ of anaplastic lymphomas; in our 20-case series, ALK- anaplastic lymphoma accounted for $55 \%{ }^{19}$. 
Table 3. Translocation table

\begin{tabular}{|c|c|c|c|}
\hline $\begin{array}{l}\text { Chromosomal } \\
\text { abnormality }\end{array}$ & ALK-associated protein & ALK staining pattern & $\begin{array}{c}\text { Percentage of occurrence in the } \\
\text { literature }\end{array}$ \\
\hline$t(2 ; 5)(p 23 ; q 35)$ & NPM & $\begin{array}{l}\text { Diffuse cytoplasmic, } \\
\text { nuclear }\end{array}$ & 84 \\
\hline$t(1 ; 2)(q 25 ; p 23)$ & TPM3 & Diffuse cytoplasmic & 13 \\
\hline inv $(2)(p 23 q 35)$ & ATIC & Diffuse cytoplasmic & 1 \\
\hline \multirow[t]{3}{*}{$t(2 ; 3)(p 23 ; q 11)$} & $T F G_{\text {xlong }}$ & & $<1$ \\
\hline & $T F G_{\text {long }}$ & Diffuse cytoplasmic & \\
\hline & $T F G_{\text {short }}$ & & \\
\hline$t(2 ; 17)(p 23 ; q 23)$ & CLTC & Cytoplasmic granular & $<1$ \\
\hline $\mathrm{t}(2 ; \mathrm{X})(\mathrm{p} 23 ; \mathrm{q} 11-12)$ & $M S N$ & Cell membrane & $<1$ \\
\hline $\mathrm{t}(2 ; 19)(\mathrm{p} 23 ; \mathrm{p} 13.1)$ & TPM4 & Diffuse cytoplasmic & $<1$ \\
\hline $\mathrm{t}(2 ; 22)(\mathrm{p} 23 ; \mathrm{q} 11.2)$ & MYH9 & Diffuse cytoplasmic & $<1$ \\
\hline$t(2 ; 17)(p 23 ; q 25)$ & AL017 & Diffuse cytoplasmic & $<1$ \\
\hline
\end{tabular}

$\mathrm{ALK}+$ and ALK- ALCL are classified as two distinct entities, given that their clinical behavior is different. As indicated in above paragraphs, ALK- neoplasms have worse prognosis than those that express ALK. The age at ALK- presentation is different than with its positive counterpart, since it predominates in middle-aged males (55 to 60 years) ${ }^{19}$; this is similar to the findings in our series, where there was predominance in males (66\%), with an average of 46 years of age.

Patients generally present with peripheral adenopathy or with extranodal involvement, mainly in the skin, the liver or digestive system (with the latter location being less common than in $A L K+A L C L)^{19}$. Of all our ALK- ALCL 11 cases, only three were extranodal: one involved the maxillary sinus, other the lung and other the intestine. ALK- ALCL exhibits a similar morphologic spectrum to that of $\mathrm{ALK}+$, but the small cell variant has not been described ${ }^{18}$.

By immunochemistry, CD30 is intensely positive (at the membrane and the Golgi zone) in all cases, and in more than half, one or more T-lymphocyte markers are expressed. Positive staining for CD3 is more common than in ALK+ ALCL. All our CD3+ cases were ALK- ALCL, which accounted for $36 \%$ of ALK- ALCLs and $20 \%$ of our entire series. In most cases, CD2 and CD4 are positive, whereas CD8-positive cases are unusual $^{2,11,19}$. In our series, T-cell markers' expression was found in all cases: CD3 in four cases, CD45RO in three, CD4 in two and CD5 in one that was also CD8-positive.

ALK- ALCL diagnosis is slightly more complex than that of $A L K+A L C L$. It has to be differentiated from R-S cell-rich Hodgkin's lymphoma, which is ALK-negative, but this is positive for CD30, CD15 and LMP-1, and weakly expresses nuclear PAX5 in most cases. However, the possibility that there may be PAX5 aberrant expression in ALK- ALCL should be considered $^{18}$. Unlike ALK+ ALCL, EMA expression is variable in ALK- ALCL and, in these cases, diagnosing ALK- ALCL is therefore suggested only in those cases with typical morphologic features and diffuse and intense CD30 and EMA immunohistochemical expression. Associated cytotoxic markers, TIA-1 granzyme $B$ and perforin, can also be positive. Both ALK+ and ALK-ALCLs are always negative for VEB, either by immunohistochemistry or in situ hybridization (LMP-1 or EBER) ${ }^{19}$.
TCR rearrangement is present in most cases, regardless of T-cell markers expression 9.19 . Although there are no recurrent primary cytogenetic anomalies, a recent study has described CCR7, CNTFR, IL22 and IL21 genes overexpression, and activation of the JAK/STAT3 pathway has been reported $^{6,9}$.

ALK- ALCL has poor response to chemotherapy based on cyclophosphamide, doxorubicin, vincristine and prednisone $(\mathrm{CHOP})^{14,19}$. Therapy with anti-CD30 agents, such as brentuximab vedotin, promises to be a good treatment alternative for ALK- $\mathrm{ALCL}^{14,19}$. In a recent study by Ferreri et al. ${ }^{18}$, ove rall survival at five years for patients with ALK- ALCL was only $49 \%$, in comparison with $70 \%$ for those with ALK+ ALCE, and $19 \%$ for those with PTCL-NOS, regardless of the type of treatment ${ }^{2,19}$.

\section{Breast implant-associated ALK- anaplastic large cell lymphoma}

Breast implant-associated ALK- ALCL was first described in 1997 by Keech and Creech, and so far there are little less than 90 published cases $^{23,24}$. This lymphoma accounts for 0.01-0.5\% of malignant tumors involving the breast $\mathrm{t}^{23,25}$.

In the 2016 revision of the WHO classification of hematopoietic neoplasms, breast implant-associated ALK- ALC is included as a different entity owing to its specific clinicopathological characteristics ${ }^{6}$. Two clinical presentation variants have been described: seroma-related ALCL, where neoplastic cells cover the implant capsule, and that is considered by some authors as the in situ form of this entity, and ALCL associated with a palpable tumor, which is the infiltrating form of the disease with no predilection for any laterality (unlike other lymphomas, which are predominant in the right breast).

Breast implant-associated ALCL commonly occurs 9-11 years after implants were placed, but it occurs only in 0.1-0.3\% of women with such implants. In our series, we had one case of this type of lymphoma, which corresponded to a 52-year old woman who presented with advanced infiltrating disease of the right breast with extension to the axillary 
region. This patient's lymphoma developed 15 years after she had undergone augmentation mammoplasty, which caused local edema and hyperemia, with secondary extension to adjacent skin. The immunophenotype is the same than that of ALK- ALCL, just as it occurred in our case, positive for CD30, EMA, CD4, with $60 \%$ Ki67 and negative for ALK.

Ramos-Gallardo et al. conducted a meta-analysis of 80 breast implant-associated ALK- ALCLs and related them to the type of material used on each patient: silicon ( $41 \%$ of cases), saline $(42.19 \%)$ and in $15.8 \%$ of cases the type of material used was not known; most common brands used in these patients were McGhan and Mento ${ }^{26}$. Treatment of this entity ranges from capsulectomy and implant removal to adjuvant therapy based on chemotherapy (CHOP) and radiotherapy. The in situ form usually has a good prognosis ${ }^{26}$.

In summary, 20 cases of ALCL are presented, classified according to the WHO new 2016 classification as ALK-1+ (9), ALK-1- (10) and breast implant-associated ALK-1 (1). It is important to know these neoplasms morphologic variability and include CD30, EMA and ALK in ALCL diagnostic analysis.

\section{REFERENCES}

1. Stein H, Mason DY, Gerdes J, et al. The expression of the Hodgkin's disease associated antigen $\mathrm{Ki}-1$ in reactive and neoplastic lymphoid tissue: evidence that Reed-Sternberg cells and histiocytic malignancies are derived from activated lymphoid cells. Blood. 1985;66(4):848-58.

2. Turner SD, Laurence L, Kenner L, Brugières L. Anaplastic large cell lymphoma in paediatric and young adult patients. $\mathrm{Br} \mathrm{J}$ Haematol. 2016;173(4):560-72.

3. Morris SW, Bullrich F, Hummel M, Pileri S, Stein H, Croce CM. Nucleophosmin (NPM) gene Rearrangements in $\mathrm{Ki}$-1-positive lymphomas. Cancer Res. 1994;54(11):2873-77.

4. Pileri SA, Piccaluga A, Poggi S, et al. Anaplastic Large Cell Lymphoma: Update of findings. Leuk Lymphoma. 1995;18(1-2):17-25.

5. Pulford K, Lamant L, Morris SW, et al. Detection of anaplastic lymphoma kinase (ALK) and nucleolar protein nucleophosmin (NPM)-ALK proteins in normal and neoplastic cells with the monoclonal antibody ALK1. Blood. 1997;89(4):1394-404.

6. Swerdlow SH, Campo E, Pileri SA, et al. The 2016 revision of the World Health Organization classification of lymphoid neoplasms. Blood. 2016;127(20):2375-90.

7. Jacobsen E. Anaplastic large-cell lymphoma, T-/null-cell type. Oncologist. 2006;11(7):831-40.

8. Schwab U, Stein H, Gerdes J, et al. Production of a monoclonal antibody specific for Hodgkin and Sternberg- Reed cells of Hodgkin's disease and a subset of normal lymphoid cells. Nature. 1982; 299(5878):65-7.

9. Kinney MC, Higgins RA, Medina EA. Anaplastic large cell lymphoma: twenty-five years of discovery. Arch Pathol Lab Med. 2011;135(1):19-43.

10. Malcolm TIM, Hodson DJ, Macintyre EA, Turner SD. Challenging perspectives on the cellular origins of lymphoma. Open Biol. 2016;6(9).

11. Bekkenk NV, Geelen FA, van Voorst Vader PC, et al. Primary and secondary cutaneous CD30+ lymphoproliferative disorders: a report from the Dutch Cutaneous Lymphoma Group on the long-term Dutch Cutaneous Lymphoma Group on the long-term follow- up data of 219 patients and guidelines for diagnosis and treatment. Blood. 2000;95(12):3653-61.

12. Kempf W. A new era for cutaneous CD30-positive T-cell lymphoproliferative disorders. Semin Diagn Pathol. 2017;34(1):22-35.

13. Laurent C, Do C, Gascoyne RD, et al. Anaplastic lymphoma kinase positive diffuse large B-cell lymphoma: a rare clinicopathologic entity with poor prognosis. J Clin Oncol. 2009;27(25):4211-6.

14. Eyre TA, Khan D, Hall GW, Collins GP. Anaplastic lymphoma kinase-positive anaplastic large cell lymphoma: current and future perspectives in adult and paediatric disease. Eur J Haematol. 2104;93(6):455-68.

15. Kodama K, Hokama M, Kawaguchi K, Tanaka Y, Hongo K. Primary ALK-1-negative anaplastic large cell lymphoma of the brain: Case re port and review of the literature. Neuropathology. 2009;29(2):166-77.

16. Stein H, Foss HD, Dürkop H, et al. CD30+ anaplastic large cell lymphōma: a review of its histopathologic, genetic, and clinical features. Blood. 2000;96(12):3681-95.

17. Falini B, Martelli MP. Anaplastic large cell lymphoma: changes in the World Health Organization classification and Perspectives for targeted therapy. Haematologica. 2009;94(7):899-900.

18. Ong DM, Cummins KD, Pham A, Grigoriadis G. PAX5-expressing ALK-negative anaplastic large cell lymphoma with extensive extranodal and nodal involvement. BMJ Case Rep. 2015;2015.

19. Ferreri AJ, Govi S, Pileri SA, Savage KJ. Anaplastic large cell lymphöma, ALK-negative. Crit Rev Oncol Hematol. 2013;85(2):206-15.

20. Liang X, Meech SJ, Odom LO, et al. Assessment of $t(2 ; 5)(p 23 ; q 35)$ Translocation and Variants in Pediatric ALK+ Anaplastic Large Cell Lymphoma. Am J Clin Pathol. 2004;121(4):496-506.

21. Morris SW, Kirstein MN, Valentine MB, et al. Fusion of a kinase gene , ALK, to a nucleolar protein gene, NPM, in non-Hodgkin's lymphoma. Science. 1994;263(5151):1281-4.

22. Minoo P, Wang HY. ALK-immunoreactive neoplasms. Int J Clin Exp Pathol. 2012;5(5):397-410.

23. Laurent C, Delas A, Gaulard P, et al. Breast implant-associated anaplastic large cell lymphoma: two distinct clinicopathological variants with different outcomes. Ann Oncol. 2016;27(2):306-14.

24. Xu J, Wei S. Breast implant-associated anaplastic large cell lymphoma. review of a distinct clinicopathologic entity. Arch Pathol Lab Med. 2014;138(6):842-6.

25. De Jong D, Vasmel WL, de Boer JP, et al. Anaplastic large-cell lymphöma in women with breast implants. JAMA. 2008;300(17):2030-5.

26. Ramos-Gallardo G, Cuenca-Pardo J, Rodríguez-Olivares E, et al. Breast Implant and Anaplastic Large Cell Lymphoma Meta-analysis. J Inyest Surg. 2017;30(1):56-65. 